\title{
Extended intervals for wet AMD patients with high retreatment needs: informing the risk during COVID-19, data from real-world evidence
}

\author{
Kelvin Yi Chong Teo $\mathbb{1}^{1,2,3} \cdot$ Vuong Nguyen ${ }^{3} \cdot$ Daniel Barthelmes ${ }^{3,4} \cdot$ Jennifer J. Arnold ${ }^{5} \cdot$ Mark C. Gillies $^{3} \cdot$ \\ Chui Ming Gemmy Cheung ${ }^{1,2}$
}

Received: 8 August 2020 / Revised: 28 October 2020 / Accepted: 10 November 2020 / Published online: 25 November 2020

(c) The Author(s), under exclusive licence to The Royal College of Ophthalmologists 2020

\begin{abstract}
Background/Objective Some clinicians may be forced to temporarily extend treatment intervals in neovascular age-related macular degeneration (nAMD) eyes with frequent retreatments to reduce the number of visits during the COVID-19 pandemic. To provide an indication of what these outcomes may be, we studied eyes with active lesions with unplanned treatment interval extensions before the pandemic occurred.

Methods We compared eyes with active disease despite $\leq 6$ weekly injections whose next injection was extended to $\geq 7$ weeks and those whose intervals were not extended. We identified 1559 (16\%) of 9602 eyes from the Fight Retinal Blindness! (FRB!) registry (2013 and 2018) that fit this criteria. Eyes were further stratified into four groups by the mean interval over the following 6 months: (1) $\leq 6$ weeks (81\%), (2) 7-9 weeks (9\%), (3) 10-12 weeks (5\%) and (4) $>12$ weeks $(5 \%)$.

Results There was a significant loss in VA in eyes extended to $>12$ weeks compared to the non-extended group (adjusted VA change, mean (95\% CI): $\leq 6$ weeks, $0.4(-1.5$ to 2.2$)$, versus $>12$ weeks, $-4.7(-7.4$ to -2.1$)$, letters, $p=0.03$ and a threefold increase in relative risk of losing $\geq 15$ letters (absolute risk ( $14 \%$ versus $4 \%, p<0.01)$ ).

Conclusion Mean VA remained stable for 6 months in eyes requiring frequent treatment despite retreatment interval extension up to 10-12 weeks. There was a significant short-term risk to vision when retreatment interval was extended beyond 12 weeks, hence extensions to this level should be considered cautiously. These data may be useful for physicians who are considering reducing visits to mitigate the risk of COVID-19.
\end{abstract}

\section{Introduction}

The coronavirus disease 2019 (COVID-19) caused by the severe acute respiratory syndrome coronavirus 2 [1] has

Chui Ming Gemmy Cheung

gemmy.cheung.c.m@singhealth.com.sg

1 Singapore Eye Research Institute, Singapore National Eye Centre, Singapore, Singapore

2 Duke-NUS Medical School, National University of Singapore, Singapore, Singapore

3 Save Sight Institute, University of Sydney, Sydney, NSW, Australia

4 University Hospital Zurich, University of Zurich, Zurich, Switzerland

5 Marsden Eye Specialist, Sydney, NSW, Australia resulted in a pandemic as declared by the World Health Organisation [2]. The lack of a vaccine or a cure has resulted in the implementation of strict and extreme social distancing measures and even lockdowns to minimise person-to-person interactions as the only viable way to prevent of virus transmission [3]. Healthcare services are also affected with reduced appointments and efforts to shorten in-clinic duration [4-8].

These measures present a particular challenge in the treatment of neovascular age-related macular degeneration (nAMD) with vascular endothelial growth factor (VEGF) inhibitors therapy as regular and frequent treatments are necessary for optimal outcomes in most patients [9-11]. To compound the problem, the mortality from COVID-19 is highest in the age group of patients with nAMD, with reported fatality rate of $8 \%$ in patients aged between 70 and 79 years and $15 \%$ in those aged 80 years or more $[12,13]$. 
Physicians are faced with a difficult decision during this time especially when managing eyes that are persistently active despite frequent injections. These make up a substantial proportion of eyes with nAMD [14-16]. Some physicians may be forced to consider extending treatment intervals in these eyes until the immediate risk of COVID19 has reduced significantly, because minimizing the potentially life-threatening risk of COVID infection may outweigh the risk of recurrence and visual loss. How big this risk of visual loss is, and over what time period it may manifest, remain unclear.

In order to provide an indication of what the outcomes of this may be, we studied eyes with active lesions that had unplanned treatment interval extensions before the pandemic occurred. We performed an analysis on real-world observational outcome data from the Fight Retinal Blindness! (FRB!) registry comparing eyes with active disease despite at least six weekly injections whose next injection was extended to 7 or more weeks and those whose intervals were not extended. These data may help retina specialists and patients arrive at a more informed management plan together during this pandemic.

\section{Methods}

Data for this analysis were obtained from the FRB! registry, which prospectively tracks real-world outcomes of nAMD in routine clinical practice, from patients treated prior to the pandemic [17]. This study included patients from Australia, New Zealand, Switzerland and Singapore. Institutional ethics approval was obtained from each country: The Human Research Ethics Committees of the University of Sydney, the Royal Victorian Eye and Ear Hospital, the Royal Australian and New Zealand College of Ophthalmologists, the Cantonal Ethics Committee Zurich, Switzerland and Singhealth, Singapore. The research described adhered to the tenets of the Declaration of Helsinki.

The detailed methodology of the FRB! registry has been previously published [17]. Briefly, the FRB! registry collects demographics, baseline clinical and outcome data from patients treated for nAMD. Data collected at baseline include the visual acuity (VA), lesion subtype, greatest linear diameter of the lesion, lesion activity, treatment administered and any ocular adverse events. VA scores were determined by the number of letters read on a logarithm of the minimum angle of resolution (logMAR) VA chart and recorded whichever reading was best: uncorrected, corrected or pinhole. Lesion subtype was determined by the treating physician as types 1,2 and $3 \mathrm{CNV}$ or polypoidal choroidal vasculopathy (PCV) using all clinical and imaging modalities available to them including optical coherence tomography and dye angiography, alone or in combination. Lesion activity was similarly graded by the treating physician based on findings from clinical examination and in combination with multimodal imaging available at each visit. Treating physicians also determined all management decisions in consultation with the patient including frequency of visits and treatment modality, thereby reflecting real-world practice.

\section{Patient selection}

Data from eyes that commenced anti VEGF therapy from 2013 to 2018 were identified from FRB! registry for analysis. All patients had an induction phase of three injections over 90 days from the commencement of treatment. Subsequent retreatment strategy was physician directed. First, we identified eyes with high retreatment requirement defined as eyes with active disease with a prior 6-week retreatment interval. Examples of scenarios where this visit may occur include persistent fluid, which may be following three injections in the initial 3 months of treatment or disease recurrence. We defined the first such visit for each patient as the start of the analysis, hereafter referred to as the "index visit". Next, all eyes required to have at least 6 months of follow up and outcomes of these eyes after 6 months from the index visit were analysed according to mean retreatment interval received after the index visit; grouped by interval length into (1) $\leq 6$ weeks, (2) 7-9 weeks, (3) 10-12 weeks and (4) $>12$ weeks. For the purpose of categorization, a window of +6 days was allowed (Fig. 1).

\section{Outcomes measures}

The primary outcome was the mean change in VA $(\log$ MAR letters) at 6 months compared to the index visit according to the different retreatment interval groups. Secondary outcomes included proportion of eyes with $\geq 5, \geq 10$ or $\geq 15$ letter loss, number of visits (including non-treatment visits, excluding visits for fellow eye if applicable) and proportion of active visits. We adjusted for baseline differences in demographic and clinical characteristics, including age, sex, baseline vision, lesion size, lesion type and lesion activity.

The specific reasons why intervals were changed were not collected, however we compared the change in vision from first treatment visit to the index visit between groups to explore whether futility was the reason behind extension. The proportion of eyes in good ( $\geq 70$ letters), middle (69-36 letters) and low ( $\leq 35$ letters) vision categories was also compared between groups.

\section{Statistical analysis}

Descriptive data are presented as mean (standard deviation [SD]), median (Q1, Q3) or number (percentage). Student's $t$ test, Chi-squared tests and Kruskal-Wallis test were used 


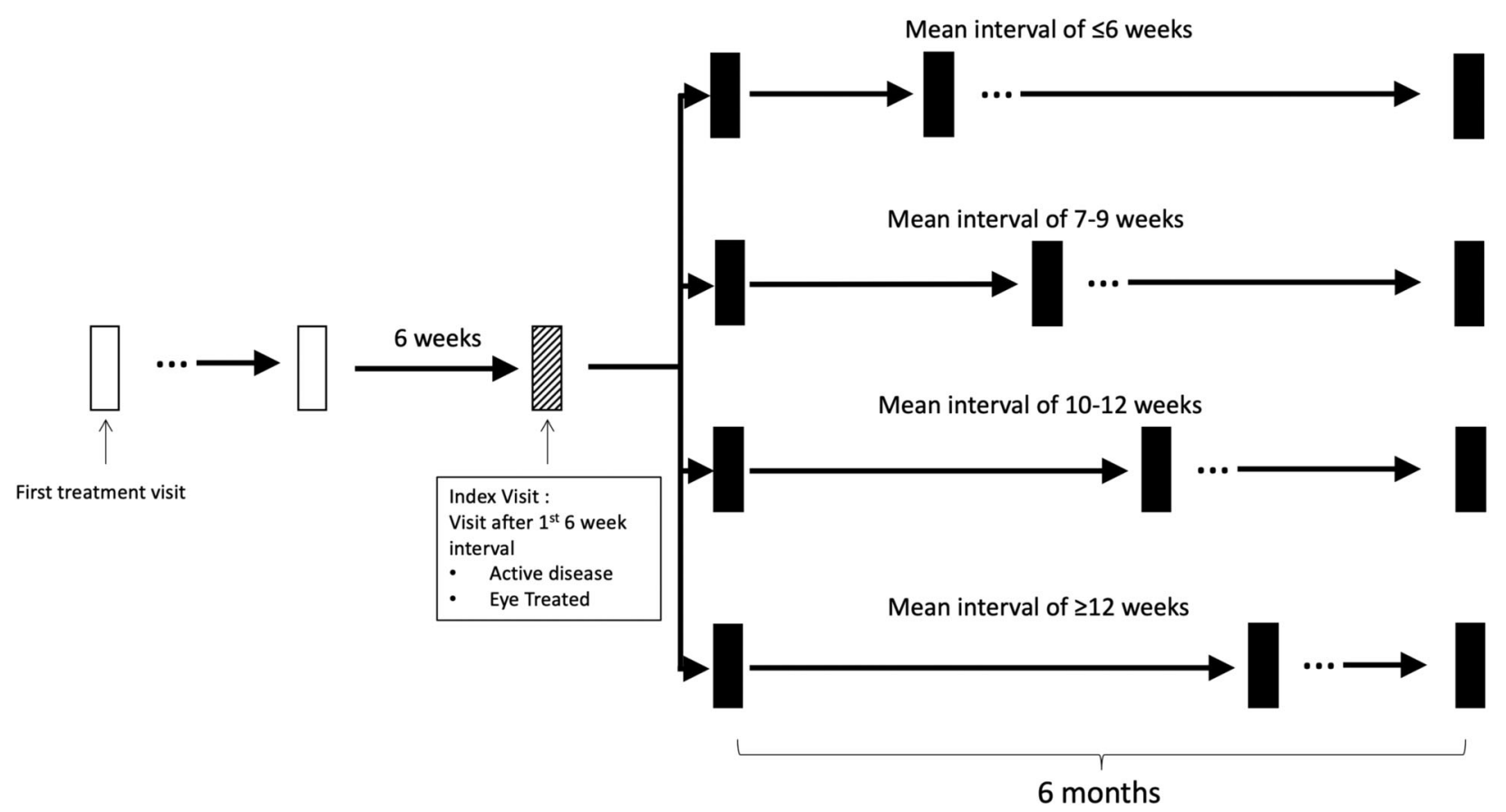

Fig. 1 Analysis criteria for patients. This figure shows the analysis criteria for pateints. Patients were divided by mean retreatment intervals after the index visit (1st visit with a 6 week interval that where disease activity was detected). Analysis was carried out by mean retreatment interval after index visit.

where appropriate to in comparisons between 6-week interval group and other interval groups. Unadjusted VA at 6 months from index visit was compared across the interval groups with pairwise comparison using ANOVA. Adjusted VA change at 6 months from index visit was compared across interval groups using linear mixed-effects regression models adjusted for age, gender index VA, lesion size and type (fixed effects), and for clustering by practice and patient (random effects). Mixed-effects logistic regression models adjusted for age, index VA, lesion size and type (fixed effects), and clustering by patient and practice (random effects), were used to compare the overall proportion of visits in which the lesion was graded as active, proportion of eyes that lost $\geq 5, \geq 10$ and $\geq 15$ letters and proportion of eyes with predominate agent type between interval groups. $p$ value $<0.05$ was considered statistically significant. Analysis was conducted using R Statistical Software (V 4.0.0) [18].

\section{Results}

\section{Baseline data-data from the first treatment visit included in FRB! registry}

Data were analysed from a total of 1559 eyes (16\%) which met the inclusion criteria for high retreatment requirement out of 9602 eyes. Most of patients $(n=1278,81 \%)$ had a mean retreatment interval of $\leq 6$ weeks. In the remaining $19 \%$, the distribution of actualized mean retreatment intervals was
7-9 weeks in 116 (9\%) eyes, 10-12 weeks in 84 (5\%) eyes and $>12$ weeks in $81(5 \%)$ eyes. Baseline characteristics at first treatment are summarised in Table 1. There was no significant difference in any demographic and clinical features between retreatment interval groups. The proportion of eyes with types 1, 2 and $3 \mathrm{CNV}$ and PCV were similar across all groups. The median time from baseline to index visit was also similar across all groups. The mean \pm SD VA change from baseline to index visit was similar between groups $(8.3 \pm 9.0$ letters, $7.8 \pm 8.1$ letters, $7.0 \pm 12.2$ letters and $6.9 \pm 11.1$ letters in the $\leq 6$ weeks, 7-9 weeks, 10-12 weeks and >12 weeks interval groups, respectively). There was no significant difference in the proportion of eyes in the good, middle and low vision groups at the index visit. There was no significant difference in the time to index visit from baseline in all interval groups. The median $(\mathrm{Q} 1, \mathrm{Q} 3)$ number of treatments from baseline was $7(5,8), 7(5,8), 6(5,9)$ and $7(5,9)$ in the $\leq 6$ weeks, 7-9 weeks, 10-12 weeks and $>12$ weeks interval groups, respectively.

\section{Visual outcomes at 6 months}

The mean \pm SD change in VA at 6 months after the index visit was $+0.8 \pm 5.4$ letters, $+0.7 \pm 7.1$ letters, $+0.5 \pm 8.0$ letters and $-2.4 \pm 8.3$ letters in eyes which received retreatment at the $\leq 6$ weeks, 7-9 weeks, 10-12 weeks and $>12$ weeks, respectively. When compared to the $\leq 6$-week retreatment group, the longest retreatment group $>12$-week interval lost significantly more letters at month 6 (adjusted 
Table 1 Baseline (on first presentation) characteristics of eyes with a 6 -week interval ( $\leq 6$ weeks) compared to increasing intervals ( $7-9$ weeks, 10-12 weeks, $>12$ weeks).

$\begin{aligned} & \leq 6 \text { weeks } \\ & \text { (Reference group) }\end{aligned}$
$7-9$ weeks

\begin{tabular}{|c|c|c|c|c|c|c|c|c|}
\hline \multicolumn{9}{|l|}{ Baseline } \\
\hline Number of eyes & $n$ & 1278 & 116 & & 84 & & 81 & \\
\hline Age, years & Mean \pm SD & $77.1 \pm 8.1$ & $78.0 \pm 8.5$ & 0.97 & $79.2 \pm 7.1$ & 0.22 & $78.6 \pm 10.2$ & 0.80 \\
\hline Gender, female & $\%$ & 59 & 60 & 0.70 & 60 & 0.86 & 51 & 0.16 \\
\hline Baseline VA, letters & Mean \pm SD & $56.3 \pm 11.5$ & $54.6 \pm 13.4$ & 0.46 & $55.7 \pm 15.3$ & 0.33 & $56.2 \pm 19.8$ & 0.12 \\
\hline Baseline GLD, $\mu \mathrm{m}$ & Mean \pm SD & $2475 \pm 2211$ & $2642 \pm 2426$ & 0.68 & $2153 \pm 1414$ & 0.23 & $2433 \pm 1320$ & 0.46 \\
\hline \multicolumn{9}{|l|}{ Lesion type } \\
\hline Type 1 & $\%$ & 58 & 60 & 0.21 & 54 & 0.46 & 52 & 0.97 \\
\hline Type 2 & $\%$ & 33 & 28 & & 39 & & 33 & \\
\hline Type 3 & $\%$ & 3 & 4 & & 0 & & 7 & \\
\hline PCV & $\%$ & 7 & 8 & & 7 & & 7 & \\
\hline $\begin{array}{l}\text { Median time from baseline to } \\
\text { index visit }\end{array}$ & $\begin{array}{l}\text { Median } \\
(\mathrm{Q} 1, \mathrm{Q} 3)\end{array}$ & $274(189,352)$ & $\begin{array}{l}258 \\
(192,315)\end{array}$ & 0.09 & $214(145,305)$ & 0.06 & $\begin{array}{l}299 \\
(187,418)\end{array}$ & 0.56 \\
\hline $\begin{array}{l}\text { Median number of } \\
\text { treatments from baseline }\end{array}$ & $\begin{array}{l}\text { Median } \\
(\mathrm{Q} 1, \mathrm{Q} 3)\end{array}$ & $7(5,8)$ & $7(5,8)$ & 0.07 & $6(5,9)$ & $<0.01$ & $7(5,9)$ & 0.02 \\
\hline \multicolumn{9}{|l|}{ Index visit } \\
\hline $\begin{array}{l}\text { VA change from first visit to } \\
\text { index visit, letters }\end{array}$ & Mean \pm SD & $8.3 \pm 9.0$ & $7.8 \pm 8.1$ & 0.19 & $7.0 \pm 12.2$ & 0.41 & $6.9 \pm 11.1$ & 0.12 \\
\hline \multicolumn{9}{|l|}{ VA group at index visit } \\
\hline High ( $\geq 70$ letters) & $\%$ & 53 & 47 & 0.23 & 57 & 0.48 & 44 & 0.13 \\
\hline Middle (69-36 letters) & $\%$ & 38 & 41 & 0.42 & 27 & 0.06 & 40 & 0.74 \\
\hline Low ( $\leq 35$ letters $)$ & $\%$ & 9 & 11 & 0.47 & 16 & 0.06 & 16 & 0.04 \\
\hline
\end{tabular}

$p$ value was derived by comparing each interval group to the $\leq 6$-week interval group.

$V A$ visual acuity, GLD greatest linear diameter.

mean letters: -2.6 versus $0.5, p=0.02$ ). Significantly more eyes in the $>12$-week interval group lost $\geq 5$ letters $(35 \%$ versus $20 \%, p<0.01), \geq 10$ letters $(19 \%$ versus $8 \%$, $p<0.01)$ and $\geq 15$ letters $(14 \%$ versus $4 \%, p<0.01)$ compared with the $\leq 6$-week interval group (Fig. 2). The changes in VA over time across groups are shown in Fig. 3.

\section{Disease activity outcomes at 6 months}

The proportion of active visits was $72,81,85$ and $70 \%$ in eyes which received retreatment at $\leq 6$ weeks, 7-9 weeks, 10-12 weeks and $>12$ weeks, respectively. Significantly more eyes in the 7-9 weeks $(p=0.01)$ and $10-12$ weeks $(p<0.01)$ interval groups had active visits compared to the $\leq 6$-week interval group.

\section{Number of visits and predominately used VEGF inhibitor}

There were significantly fewer visits (including nontreatment visits) over 6 months in eyes with progressively long intervals. The median number of visits was 7, 6, 4 and 4 in the $\leq 6$ weeks, 7-9 weeks, $10-12$ weeks and $>12$ weeks groups, respectively. There was no difference between the distributions of the predominate VEGF inhibitor (bevacizumab, ranibizumab and aflibercept) used between the interval groups. Results are summarised in Table 2.

\section{Visual outcomes at 12 months}

\section{All eyes included in the initial analysis had a 12-month outcome reported}

The mean \pm SD change in VA at 12 months after the index visit was $+0.2 \pm 6.9$ letters, $-0.1 \pm 8.9$ letters, $-0.7 \pm 10.7$ letters and $-1.4 \pm 10.8$ letters in eyes which received retreatment at the $\leq 6$ weeks, 7-9 weeks, 10-12 weeks and $>12$ weeks, respectively. There was no significant difference in VA change between $\leq 6$-week retreatment groups and other retreatment groups.

\section{Discussion}

We used the FRB! dataset in this analysis to investigate the risk of visual loss in patients with high retreatment 


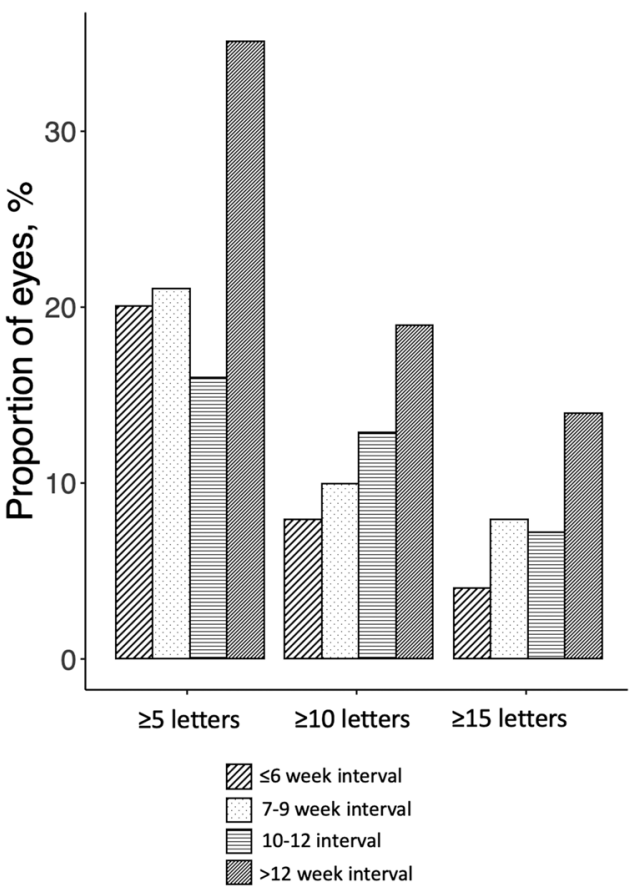

Fig. 2 Proportion of patients with $\geq 5, \geq 10$ and $\geq 15$ letters lost divided by interval group. This bar chart shows the proportion of patients with varying letters lost divided by interval group. There is consistently more patients in the $>12$ week interval group that lost letters in all categories compared to the other retreatment intervals.

requirement regarding if the interval between treatments were temporarily and aggressively extended. We defined high retreatment requirement by the presence of activity despite receiving six weekly treatments. Our findings may be of interest to physicians who are considering extending the retreatment interval during the COVID-19 pandemic for these patients despite potentially requiring frequent retreatments to control their disease. We found that that on average, vision can remain relatively stable for up to 6 months when patients were extended up to 10-12 weekly injections. There were also significantly fewer visits in the 10-12-week group with four visits compared to seven visits in the $\leq 6$-week interval group. This suggests that more than two visits can be saved by aggressive extensions while maintaining vision. Patients whose treatment interval was extended $>12$ weeks, however, lost about 4.7 letters on average. More importantly, the relative risk of devastating vision loss of $\geq 15$ letters was 2-3 times higher in patients on $>12$-week interval group versus the group that was not extended.

In the longer term results, the vision up to 12 months after index visit was not significantly different between interval groups and $\leq 6$-week interval group. It appeared that even patients in the $>12$-week interval group managed to regain some vision over the following 6 months. This suggest that some patients may have 'salvageable' vision loss even at the longest retreatment interval but this would depend on many factors including the treatment regimen during the following 6 months, disease and patient characteristics that are beyond the scope of this analysis.

Our results focused on the group of eyes with a high retreatment requirement as defined in our inclusion criteria. This group of patients constituted $16 \%$ of the eligible FRB! cohort, but likely represent the most challenging cases. Even with the most intensive treatment at $\leq 6$ weeks, $20 \%$ of these patients lost five letters or more, and $70 \%$ had disease activity. This group of patients also had a median of 7 visits during the 6-month study period. Maintaining this high frequency of visits during the current pandemic may inadvertently put patients at greater risk of exposure and contracting COVID-19. A small mismatch between disease activity in the $>12$-week interval group ( $72 \%$ of visits graded as active) and the $\leq 6$-week interval group (70\% of visits graded as active) and visual outcome was noted. We propose that this discrepancy may be due to the development of poor prognostic features like macular atrophy and or sub-retinal fibrosis in the longer interval group limiting their visual gains. This difference in proportion of active visits, however, was small and not statistically significant.

These results should be interpreted in the context of risk versus benefit ratio for each individual patient. We recognise the current evidence from both clinical trial and realworld evidence that clearly demonstrated the detrimental effects of sub-optimal treatment [19-22] and that appropriate and timely treatment is important for favourable visual outcomes in nAMD [23-29]. Our group has advocated strongly for this and has demonstrated this in several studies $[21,30,31]$. On the other hand, these data will help physicians evaluate the risk of vision loss associated with each extension interval and should be taken together with other factors such as prevalence of COVID-19 within the community, individual patient's systemic comorbidities, VA in the fellow eye and visual potential of the treated eye to better inform the physician and patient when deciding on an acceptable retreatment interval.

These results can also provide reference for professional bodies when crafting recommendation and guidelines. Currently, there is no consensus on the approach to the approach to management of patients with AMD during this pandemic $[32,33]$. A variety of strategies have been proposed including maintaining current practice [34] and 8week treatment with minimal investigations [35]. The lack of clear consistent guidance is a result of firstly, a lack of evidence in an unprecedented crisis that has forced physicians to consider less than ideal treatment. The Canadian society of ophthalmology uses currently available clinical trial evidence [36] to infer the best practice for a period of lockdown, for example, suggesting aggressive 4-week extension with TNE tolerating some fluid as per the ALTAIR study [16] or quarterly intervals after loading as per PIER study [37]. However, these strategies may not 
Fig. 3 Visual acuity change from baseline over time in each interval group. The dotted line represents the median day of index visit, and the dash line indicates 180 days after index visit.
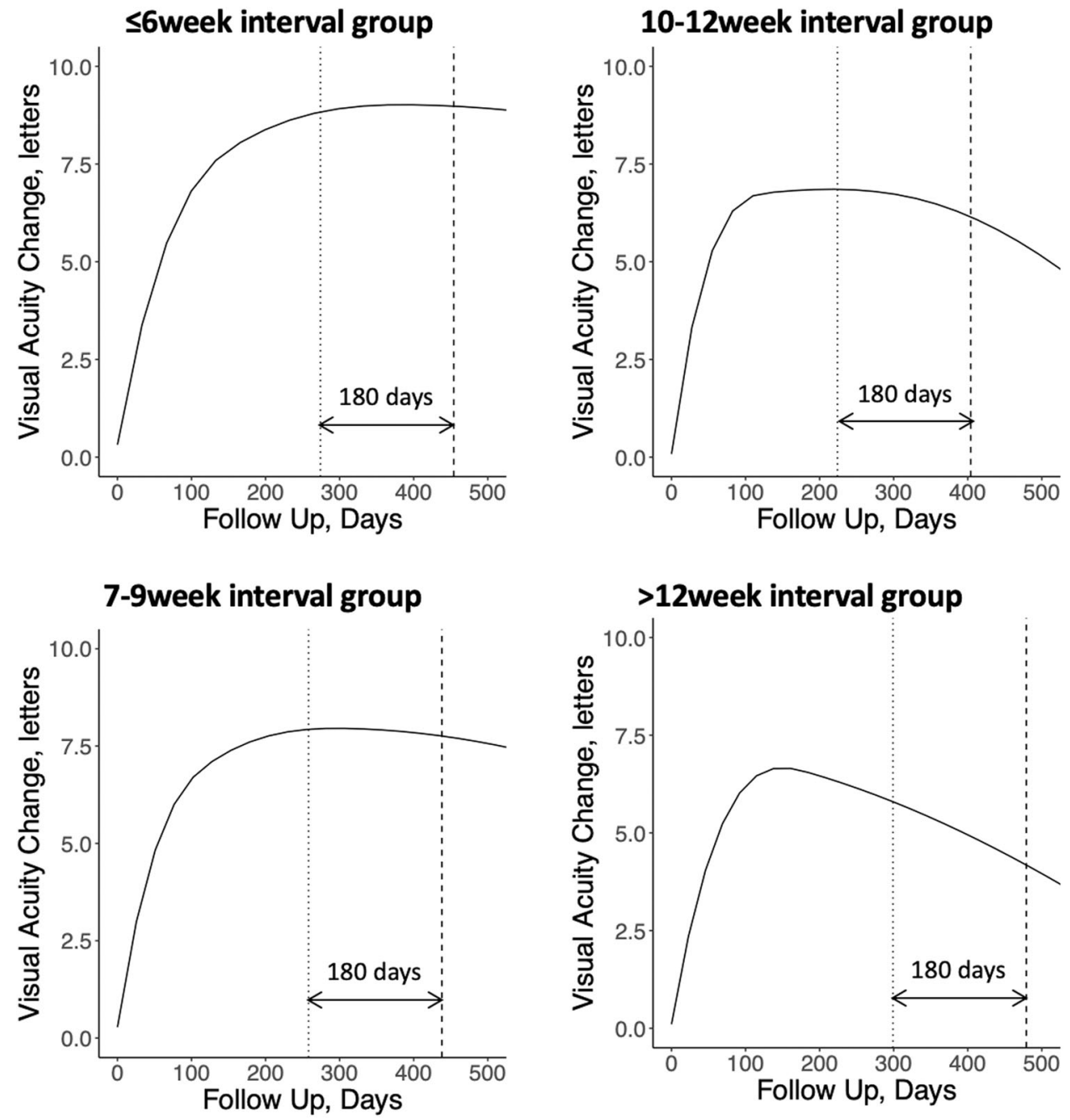

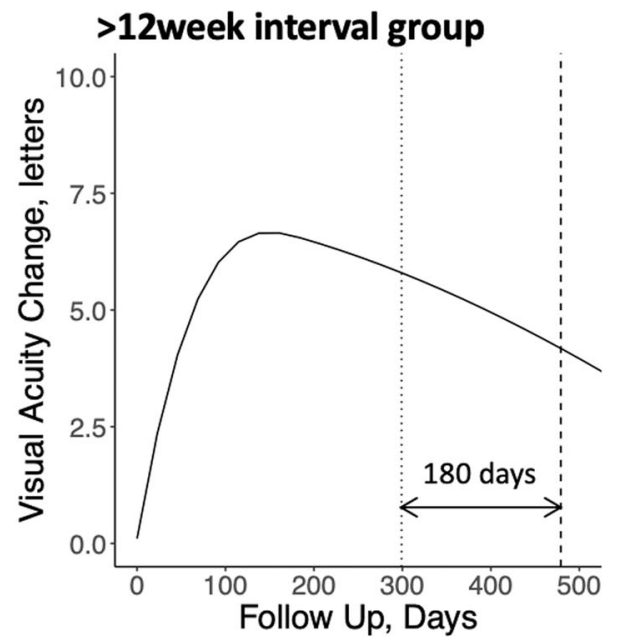

directly relate to the current situation. Secondly, there are varying levels of COVID prevalence in different countries with the situation rapidly evolving. Nonetheless, the general guidance should be to practice as much social distancing as safely possible and discourage unnecessary hospital visits.

The strengths of this study are that it derives the outcomes from a large real-world dataset. The heterogeneity of patient characteristics and physician-driven regimens contribute to the generalisability of these results. Only through large real-world datasets such as this, can we observe deviations from recommended treatments which in turn can help to guide our management of nAMD during unprecedented crisis such as this one. These deviations are unlikely to be intentional and likely due to unforeseeable circumstances such as periods of hospitalisation or illness.

There are several limitations to this analysis. Firstly, and most importantly, the cohort analysed is different from those that are extended during the COVID pandemic. This is because the reasons and circumstances for sub-optimal treatment in our study cohort, which constitutes only a small proportion of patients on FRB! registry, are unusual and not generalisable. Nonetheless, this analysis can be used a reference as there is a little evidence of treatments for nAMD during this unprecedented time. Another limitation as eluded to previously, is that the reason behind the aggressive extensions for each patient was not collected as part of the registry, and is unrelated to the COVID-19 situation. The majority of patients on the FRB! registry are optimally treated, however there is a small proportion that are suboptimally treated. The reasons for sub-optimal treatment could be multifactorial and are well known to practising physicians, with unplanned extension from missed appointments due to management of comorbidities that patients receiving injections then to have, or conscious extension of intervals due a variety of reasons related to the high burden of treatment. One reason could be futility of treatment, but this is unlikely since each of the three groups that were extended had mean VA at the index visit similar to that of the eyes that were not extended. Another reason could be due to a change in practice patterns in late 2018 with the FLUID study, which reported that eyes with subretinal fluid alone could have treatment intervals extended 


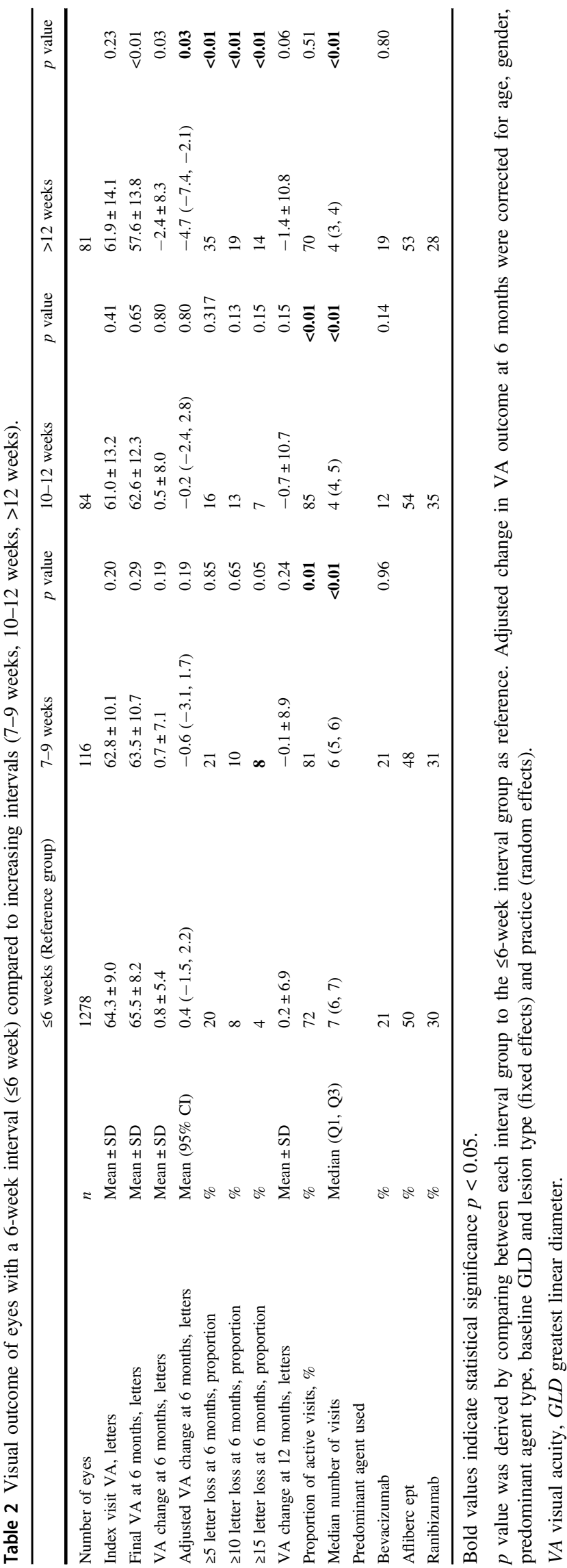

with similar visual outcomes as conventional TNE extension criteria, which require inactive disease. Some patients in our cohort may have been extended based on the FLUID criteria but this characteristic of activity was not available to track in the FRB! registry, which started in 2006, until 2017. Finally, the 6-month outcomes reported here may not reflect the longer term effect on vision. It is also unclear if vision loss is salvageable if treatment is promptly restarted after a relatively brief period of treatment interval extension. However, as the COVID-19 pandemic is still evolving, we feel the 6-month results are the most immediately applicable data to inform clinicians who are currently navigating this situation.

In conclusion, this analysis provides information on the risk of lengthening the interval in eyes with high retreatment requirements within the first year of treatment. Six-month vision outcomes in eyes with high retreatment requirements whose treatment interval were extended up to 10-12 weeks were similar to $\leq 6$-week intervals. There was a risk of vision loss if the interval was extended $>12$ weeks, so such an interval should be considered cautiously in these eyes. Further analysis of patients' treatment journey through the pandemic and afterwards will be needed to address the question of whether vision can be salvaged if proper treatment is reinstituted. We hope that this information may help physicians, patients and healthcare systems make informed decisions on the difficult task of weighing the risk and benefit of vision loss from nAMD versus mortality from COVID-19 over a lockdown/social distancing period.

\section{Summary}

\section{What was known before}

- Regular appropriately timed treatments are still important for optimal outcomes for nAMD. nAMD patients are vulnerable to COVID-19 infection and may not be able to attend their treatment visits.

\section{What this study adds}

- Good outcomes can be maintained with extension of visits up to 12 weeks between treatments despite active disease, this helps guide treatment regimens over COVID-19 pandemic lockdowns.

Acknowledgements Fight Retinal Blindness! investigators: Auckland District Health Board, New Zealand (Dr D. Squirrell); Armadale Eye Clinic, Victoria (Dr A. Cohn); Lion's Eye Institute, Western Australia (Dr F. Chen, Dr T. Isaac, Professor I. McAllister); Auckland Eye, New Zealand (Dr A. McGeorge); Bundaberg Eye Clinic, Queensland (Dr I. McLean); Cairns Eye Surgery, Queensland (Dr A. Field); Canberra 
Hospital, Australian Capital Territory (Dr C. Dayajeewa, Dr J. Wells); Care Foresight, New South Wales (Dr A. Dunlop); Caulfield Eye Clinic, Victoria (Dr C. Ng); Central Coast Eye Specialist, New South Wales (Dr S. Young); Centre for Eye Research Australia, Victoria (Professor R. Guymer); Coastwide Eye Surgery, New South Wales (Dr R. Ferrier); Crest Eye Associates, New Zealand (Dr J. Ah-Chan); Doncaster Eye Center, Victoria (Dr L. Chow); Dr Alex Amini's Practice, Victoria (Dr A. Amini); Dr Clarks Practice, New South Wales (Dr G. Clark); Dr Nadia Wittles Practice, South Australia (Dr N. Wittles); Dr Phillip Windle, Queensland (Dr P. Windle); Eye Associates, New South Wales (Dr M. Gillies, Dr A. Hunt); Eye Surgeons Miranda, New South Wales (Dr A. Hunt); Eyemedics (Wayville), South Australia (Dr K. Billing, Dr J. Chen, Dr S. Lake, Dr J. Landers, Dr M. Perks, Dr R. Phillips, Dr N. Saha); Gladesville Eye Specialists, New South Wales (Dr S. Young); Hawthorn Eye Clinic, Victoria (Dr L. Chow); Hornsby Eye Specialists, New South Wales (Dr S. Lal); Les Manning, Queensland (Dr L. Manning); Marsden Eye Specialists, New South Wales (Dr J. Arnold); Midwest Ophthalmology, New South Wales (Dr K. Tang); Mona Vale Eye Centre, New South Wales (Dr C. Lim); Nepean Valley Eye Surgeons, New South Wales (Dr G. Banerjee); North Queensland Retina, Queensland (Dr I. Reddie); Port Macquarie Eye Centre, New South Wales (Dr J. Game); Retina \& Macula Specialists (Miranda), New South Wales (Dr M. Chilov); Retina Associates, New South Wales (Dr S. Fraser-Bell, Dr A. Fung, Professor A. Hunyor, Dr C. Younan); Retina Consultants, New South Wales (Dr S. Young); Retina Specialists, New Zealand (Dr R. Barnes, Dr D. Sharp, Dr A. Vincent); Singapore National Eye Centre, Singapore (Dr G. Cheung); Specialist Eye Group, Victoria (Dr L. Chow, Dr A Cohn); Strathfield Retina Clinic, New South Wales (Dr C. Lim); Sydney Eye Hospital, New South Wales (Dr S. Fraser-Bell, Dr J. Wong); University Hospital Zurich, Switzerland (Dr D. Barthelmes); Victoria Parade Eye Consultants, Victoria (Dr M. Daniell, Professor R. Guymer, Dr A. Harper, Dr L. Lim, Dr J. ODay); Victorian Eye Surgeons, Victoria (Dr A. Cohn) and Visionary Eye Specialists, New South Wales (Dr C. Hooper).

Funding Supported by a grant from the Royal Australian NZ College of Ophthalmologists Eye Foundation (2007-2009), a grant from the National Health and Medical Research Council, Australia, (NHMRC 2010-2012) and a grant from the Macula Disease Foundation, Australia. MCG is a Sydney Medical Foundation Fellow and is supported by an NHMRC practitioner fellowship. DB was supported by the Walter and Gertrud Siegenthaler Foundation Zurich, Switzerland, and the Swiss National Foundation. CMGC is supported grant by a grant from the National Medical Research Council (Open Fund Large Collaborative grant no: NMRC/LCG/0042018).

\section{Compliance with ethical standards}

Conflict of interest MCG and DB are inventors of the software used to collect the data for this analysis, the copyright is owned by the University of Sydney.

Publisher's note Springer Nature remains neutral with regard to jurisdictional claims in published maps and institutional affiliations.

\section{References}

1. Lu R, Zhao X, Li J, Niu P, Yang B, Wu H, et al. Genomic characterisation and epidemiology of 2019 novel coronavirus: implications for virus origins and receptor binding. Lancet. 2020;395:565-74.
2. World Health Organisation. Coronavirus disease (COVID-2019) situation reports—situation report 51. Geneva, Switzerland: World Health Organisation; 2019.

3. Ahmed F, Zviedrite N, Uzicanin A. Effectiveness of workplace social distancing measures in reducing influenza transmission: a systematic review. BMC Public Health. 2018;18:518.

4. Wilder-Smith A, Freedman DO. Isolation, quarantine, social distancing and community containment: pivotal role for old-style public health measures in the novel coronavirus (2019-nCoV) outbreak. J Travel Med. 2020;27:taaa020. https://doi.org/10.1093/ $\mathrm{jtm} / \mathrm{taaa} 020$.

5. Steffens I. A hundred days into the coronavirus disease (COVID19) pandemic. Euro Surveill. 2020;25:2000550. https://doi.org/10. 2807/1560-7917.ES.2020.25.14.2000550.

6. Leung K, Wu JT, Liu D, Leung GM. First-wave COVID-19 transmissibility and severity in China outside Hubei after control measures, and second-wave scenario planning: a modelling impact assessment. Lancet. 2020;395:1382-93. https://doi.org/10.1016/ S0140-6736(20)30746-7.

7. Cowling BJ, Ali ST, Ng TWY, Tsang TK, Li JCM, Fong MW, et al. Impact assessment of non-pharmaceutical interventions against coronavirus disease 2019 and influenza in Hong Kong: an observational study. Lancet Public Health. 2020;5:e279-e288. https://doi.org/10.1016/S2468-2667(20)30090-6.

8. Wee LE, Conceicao EP, Sim XYJ, Aung MK, Tan KY, Wong HM, et al. Minimizing intra-hospital transmission of COVID-19: the role of social distancing. J Hosp Infect. 2020;105:113-5. https://doi.org/ 10.1016/j.jhin.2020.04.016.

9. Chakravarthy U, Harding SP, Rogers CA, Downes SM, Lotery $\mathrm{AJ}$, Wordsworth $\mathrm{S}$, et al. Ranibizumab versus bevacizumab to treat neovascular age-related macular degeneration: one-year findings from the IVAN randomized trial. Ophthalmology. 2012;119:1399-411.

10. Martin DF, Maguire MG, Fine SL, Ying GS, Jaffe GJ, Grunwald $\mathrm{JE}$, et al. Ranibizumab and bevacizumab for treatment of neovascular age-related macular degeneration: two-year results. Ophthalmology. 2012;119:1388-98.

11. Holz FG, Amoaku W, Donate J, Guymer RH, Kellner U, Schlingemann RO, et al. Safety and efficacy of a flexible dosing regimen of ranibizumab in neovascular age-related macular degeneration: the SUSTAIN study. Ophthalmology. 2011;118:663-71.

12. Guan WJ, Ni ZY, Hu Y, Liang WH, Ou CQ, He JX, et al. Clinical Characteristics of Coronavirus Disease 2019 in China. N Engl J Med. 2020;382:1708-20. https://doi.org/10.1056/NEJMoa 2002032.

13. Wu Z, McGoogan JM. Characteristics of and Important Lessons From the Coronavirus Disease 2019 (COVID-19) Outbreak in China: Summary of a Report of 72314 Cases From the Chinese Center for Disease Control and Prevention. JAMA. 2020;323:1239-42. https://doi.org/10.1001/jama.2020.2648.

14. Barthelmes D, Nguyen V, Daien V, Campain A, Walton R, Guymer R, et al. Two year outcomes of "treat and extend" intravitreal therapy using aflibercept preferentially for neovascular age-related macular degeneration. Retina. 2018;38:20-28.

15. Guymer RH, Markey CM, McAllister IL, Gillies MC, Hunyor AP, Arnold JJ, et al. Tolerating subretinal fluid in neovascular agerelated macular degeneration treated with ranibizumab using a treat-and-extend regimen: FLUID study 24-month results. Ophthalmology. 2019;126:723-34.

16. Ohji M, Takahashi K, Okada AA, Kobayashi M, Matsuda Y, Terano Y, et al. Efficacy and safety of intravitreal aflibercept treatand-extend regimens in exudative age-related macular degeneration: 52- and 96-week findings from ALTAIR: a randomized controlled trial. Adv Ther. 2020;37:1173-87. 
17. Gillies MC, Walton R, Liong J, Arnold JJ, McAllister I, Morlet N, et al. Efficient capture of high-quality data on outcomes of treatment for macular diseases: the Fight Retinal Blindness! Project. Retina. 2014;34:188-95.

18. Foundation for Statistical Computing. R: a language and environment for statistical computing [computer program]. Vienna, Austria: R Foundation for Statistical Computing; 2017.

19. Johnston RL, Carius HJ, Skelly A, Ferreira A, Milnes F, Mitchell P. A retrospective study of ranibizumab treatment regimens for neovascular age-related macular degeneration (nAMD) in Australia and the United Kingdom. Adv Ther. 2017;34:703-12.

20. Lanzetta P, Cruess AF, Cohen SY, Slakter JS, Katz T, Sowade O, et al. Predictors of visual outcomes in patients with neovascular age-related macular degeneration treated with anti-vascular endothelial growth factor therapy: post hoc analysis of the VIEW studies. Acta Ophthalmol. 2018;96:e911-8.

21. Nguyen CL, Gillies MC, Nguyen V, Daien V, Cohn A, Banerjee G, et al. Characterization of poor visual outcomes of neovascular agerelated macular degeneration treated with anti-vascular endothelial growth factor agents. Ophthalmology. 2019;126:735-42.

22. Chong Teo KY, Saxena N, Gan A, Wong TY, Gillies MC, Chakravarthy U, et al. Detrimental Effect of Delayed Re-treatment of Active Disease on Outcomes in Neovascular Age-Related Macular Degeneration: The RAMPS Study. Ophthalmol Retina. 2020;4:871-80. https://doi.org/10.1016/j.oret.2020.03.017.

23. Cohen SY, Mimoun G, Oubraham H, Zourdani A, Malbrel C, Quere $\mathrm{S}$, et al. Changes in visual acuity in patients with wet age-related macular degeneration treated with intravitreal ranibizumab in daily clinical practice: the LUMIERE study. Retina. 2013;33:474-81.

24. Eldem B, Lai TYY, Ngah NF, Vote B, Yu HG, Fabre A, et al. An analysis of ranibizumab treatment and visual outcomes in realworld settings: the UNCOVER study. Graefes Arch Clin Exp Ophthalmol. 2018;256:963-73.

25. Holz FG, Bandello F, Gillies M, Mitchell P, Osborne A, Sheidow $\mathrm{T}$, et al. Safety of ranibizumab in routine clinical practice: 1-year retrospective pooled analysis of four European neovascular AMD registries within the LUMINOUS programme. Br J Ophthalmol. 2013;97:1161-7.

26. Mitchell P, Liew G, Gopinath B, Wong TY. Age-related macular degeneration. Lancet. 2018;392:1147-59.

27. Invernizzi A, Nguyen V, Teo K, Barthelmes D, Fung A, Vincent A, et al. Five-year real-world outcomes of occult and classic choroidal neovascularization: data from the Fight Retinal Blindness! Project. Am J Ophthalmol. 2019;204:105-12.

28. Rakic JM, Leys A, Brie H, Denhaerynck K, Pacheco C, Vancayzeele $\mathrm{S}$, et al. Real-world variability in ranibizumab treatment and associated clinical, quality of life, and safety outcomes over 24 months in patients with neovascular age-related macular degeneration: the HELIOS study. Clin Ophthalmol. 2013; $7: 1849-58$.

29. Rao P, Lum F, Wood K, Salman C, Burugapalli B, Hall R, et al. Real-world vision in age-related macular degeneration patients treated with single anti-VEGF drug type for 1 year in the IRIS Registry. Ophthalmology. 2018;125:522-8.

30. Essex RW, Nguyen V, Walton R, Arnold JJ, McAllister IL, Guymer RH, et al. Treatment patterns and visual outcomes during the maintenance phase of treat-and-extend therapy for age-related macular degeneration. Ophthalmology. 2016;123:2393-400.

31. Nguyen V, Vaze A, Fraser-Bell S, Arnold J, Essex RW, Barthelmes D, et al. Outcomes of suspending VEGF inhibitors for neovascular age-related macular degeneration when lesions have been inactive for 3 months. Opthamol Retina. 2019;3:623-8.

32. Chandra S, Flanagan D, Hingorani M, Lotery A, Sivaprasad S. COVID19 and ophthalmology: a brief summary of the literature. Eye (Lond). 2020;34:1200-2. https://doi.org/10.1038/s41433020-0956-3.

33. Teo KYC, Chan RVP, Cheung CMG. Keeping our eyecare providers and patients safe during the COVID-19 pandemic. Eye (Lond). 2020;34:1161-2. https://doi.org/10.1038/s41433-0200960-7.

34. Korobelnik JF, Loewenstein A, Eldem B, Joussen AM, Koh A, Lambrou GN, et al. Guidance for anti-VEGF intravitreal injections during the COVID-19 pandemic. Graefes Arch Clin Exp Ophthalmol. 2020;258:1149-56. https://doi.org/10.1007/s00417-02004703-x.

35. Royal College of Ophthalmologists. Medical retinal management plans during COVID-19. Royal College of Ophthalmologists. https://www.rcophth.ac.uk/wp-content/uploads/2020/03/MedicalRetinal-Management-Plan-during-COVID-19-UPDATED300320-1-3.pdf. Accessed 30 Mar 2020.

36. Maberley DMZ, Chaudhary V, Kertes P, Hooper P, Whelan J, Kherani A, et al. Additional considerations to help manage the anti-VEGF injection burden during the COVID-19 pandemic. Association of Canadian University Professors of Ophthalmology. https://www.cosprc.ca/resource/additional-considerations-to-helpmanage-the-anti-vegf-injection-burden-during-the-covid-19-pa ndemic/. Accessed 4 Apr 2020.

37. Regillo CD, Brown DM, Abraham P, Yue H, Ianchulev $T$, Schneider S, et al. Randomized, double-masked, sham-controlled trial of ranibizumab for neovascular age-related macular degeneration: PIER Study year 1. Am J Ophthalmol. 2008;145: 239-48. 